\title{
Avaliação físico-química e sensorial de bebidas com diferentes proporções de extratos de soja e de arroz
}

\author{
Physicochemical and sensorial evaluation of beverages with different proportions of soy and rice extracts
}

\author{
Leandra Zafalon JAEKEL ${ }^{1 *}$, Rosane da Silva RODRIGUES ${ }^{2}$, Amanda Pinto da SILVA ${ }^{2}$
}

\begin{abstract}
Resumo
O interesse dos consumidores por alimentos que além de nutrir promovam benefícios à saúde tem aumentado nos últimos anos, destacando-se o interesse pela soja. No entanto, características sensoriais indesejáveis, como sabor a "feijão cru" e hábitos alimentares específicos da população, são fatores que ainda prejudicam sua inserção na dieta usual. A aceitação de produtos à base de soja pode aumentar com a associação a aditivos ou outras matérias-primas. $\mathrm{O}$ arroz mostra-se excelente alternativa: por apresentar sabor suave, pode contribuir para a obtenção de produtos de soja com propriedades sensoriais adequadas, aumentar o valor agregado, bem como incentivar o consumo da soja. Objetivouse determinar características físico-químicas e avaliar sensorialmente bebidas de soja e arroz. Foram desenvolvidas três formulações com diferentes proporções de extratos de soja e de $\operatorname{arroz}\left(30: 70,50: 50\right.$ e 70:30, m/m), padronizando-se o teor de sólidos solúveis em $10{ }^{\circ} \mathrm{Brix}$, por adição de sacarose. A bebida 70S:30A apresentou teores significativamente maiores de proteínas, cinzas, fibra bruta, $\mathrm{pH}$, acidez e menores de açúcares redutores e totais. A mesma bebida salientou-se também sensorialmente, apresentando maior preferência e índice de aceitabilidade. É possível elaborar bebida de soja e arroz com características tecnológicas, nutricionais e sensoriais adequadas.
\end{abstract}

Palavras-chave: bebidas de soja e arroz; alimentos funcionais; análise sensorial; composição química.

\begin{abstract}
The interest of consumers for foods that besides nourishment provide health benefits has increased in the recent years, especially soybean. However, sensory characteristics such as the undesirable "raw beans" flavor and particular dietary habits of the population are factors that still hinder the inclusion of soybean in the usual diet. The acceptance of soy products may increase with the association of additives or other raw materials such as rice, which has proved an excellent alternative to produce a mild taste and contribute to the obtention of soy products with adequate sensory properties, increase its aggregated value, and encourage its consumption. The objective of this study was to determine the physicochemical characteristics and to perform sensory analysis of soy and rice beverages. Three formulations were developed with different proportions of soy and rice extracts $(30: 70,50: 50$, and $70: 30, \mathrm{~m} / \mathrm{m})$ standardizing the content of soluble solids at $10^{\circ} \mathrm{Brix}$ through the addition of sucrose. The 70S:30A beverage showed significantly higher levels of protein, ash, fiber, $\mathrm{pH}$, acidity, and lower levels of reducer and total sugars. The sensory results of this same beverage showed greater preference and acceptability index. The proposed methodology enabled the obtention of a soy and rice beverage with appropriate technological, nutritional, and sensory characteristics.
\end{abstract}

Keywords: soy and rice beverages; functional foods; sensory analysis; chemical composition.

\section{Introdução}

Nos últimos anos tem-se verificado um interesse crescente dos consumidores por alimentos que além da função básica de nutrir promovam efeitos benéficos à saúde (PRATES; MATEUS, 2002; FRANCO, 2006). As tendências globais apontam um crescimento do mercado em altas taxas, pela conquista natural de novos adeptos a estes alimentos, pelo surgimento quase diário de boas notícias provenientes das pesquisas científicas relacionando os alimentos funcionais à saúde e qualidade de vida, além da introdução de novos produtos no mercado, o que amplia as alternativas mercadológicas (GAZONI, 2006).

Neste contexto destaca-se a soja, cujas evidências benéficas à saúde demonstradas na última década fizeram com que ganhasse reconhecimento por diversas agências de saúde. O mercado de soja apresenta forte crescimento no segmento de bebidas, quando comparado a produtos tradicionais. Segundo dados da ACNielsen, o mercado de bebidas à base de soja apresentou, entre 2004 e 2006, um crescimento de $93 \%$, enquanto o mercado de sucos prontos cresceu 25\% no mesmo período (IEPC, 2007). Tal aumento no consumo de bebidas de soja prontas para o consumo decorre da busca do consumidor por produtos saudáveis e práticos, das novas tecnologias de produção que possibilitam a obtenção de bebidas com melhores características sensoriais e da oferta constante de produtos com sabores diferenciados (BARBOSA, 2007).

Departamento de Tecnologia dos Alimentos, Universidade Estadual de Campinas - UNICAMP, Cidade Universitária "Zeferino Vaz", s/n, CP 6121, CEP 13083-862, Campinas - SP, Brasil, E-mail: leandra@fea.unicamp.br

2 Departamento de Ciência de Alimentos, Universidade Federal de Pelotas - UFPEL, Campus Universitário, CP 354, CEP 96010900, Pelotas - RS, Brasil

${ }^{*}$ A quem a correspondência deve ser enviada 
Contudo, existem restrições à inclusão destes produtos na dieta, devido à presença de características sensoriais indesejáveis como sabor a "feijão cru", adstringência e presença de oligossacarídeos não digeríveis como estaquiose e rafinose, que aumentam a flatulência em alguns indivíduos, bem como aos hábitos alimentares da população, que ainda não está familiarizada ao consumo e às características sensoriais da soja (MORAES; SILVA, 1996; RODRIGUES, 2003; BARBOSA, 2007; MACHADO, 2007).

Inúmeras tecnologias têm mostrado êxito na obtenção de extratos com melhores características sensoriais, porém foi constatado que sua aceitação é aumentada quando associados a aditivos, ingredientes ou a outra matéria-prima que confira características de sabor e aroma diferentes daqueles inerentes ao extrato de soja puro (RODRIGUES, 2003).

A combinação de soja com cereais é desejável, pois, além de adequado balanceamento de aminoácidos essenciais (FERNANDES et al., 2000; MAIA et al., 2000; WANG et al., 2000), pode-se obter sabor e aroma mais agradáveis. Dentre os cereais, o arroz destaca-se pela presença marcante na dieta usual do País e, por apresentar sabor suave, pode contribuir para a obtenção de produtos de soja com propriedades sensoriais adequadas, aumentar o valor agregado, bem como incentivar o consumo da soja na alimentação humana. Além disso, o arroz tem se destacado por apresentar alegação de funcionalidade, demonstrada em inúmeras pesquisas (CHAMP; FAISANT, 1996; GOÑI et al., 1996; MAZZA, 1998; THOMPSON, 2000; WILSON et al., 2000; NAMRATHA; ASNA; PRASAD, 2002; LOBO; SILVA, 2003; BERGER et al., 2004; WALTER; SILVA; DENARDIN, 2005; SALGADO et al., 2005a, b; MITRA; BHATTACHARYA; ROY, 2007).

Em alguns países orientais são comercializadas bebidas à base de arroz, conhecidas como extrato, "leite" ou bebida de arroz, caracterizadas como um produto de sabor suave e levemente adocicado, decorrente da hidrólise do amido em maltose e em outros açúcares, pela ação de enzimas. A tecnologia é factível, o que favorece a sua produção em regiões onde a produção de arroz é expressiva, como no Brasil, ampliando e diversificando o consumo deste cereal.

A qualidade sensorial dos produtos é um dos fatores mais importantes, por ser decisiva na escolha de bebidas à base de soja pelo consumidor, especialmente relacionada ao atributo sabor, que se sobrepõem às demais propriedades sensoriais (BORRMANN et al., 2006).

Este trabalho visou determinar as características físicoquímicas e avaliar sensorialmente bebidas elaboradas com diferentes proporções de extratos de soja e de arroz.

\section{Material e métodos}

\subsection{Material}

Foram utilizados grãos de soja (Glycine max (L.) Merril) "BRS 213", fornecidos pela EMBRAPA Soja, Londrina - PR. A escolha da cultivar foi baseada na sua baixa atividade de lipoxigenases, enzimas responsáveis pelo desenvolvimento de sabor desagradável, o que possibilita a obtenção de produtos de soja com sabor e aroma agradáveis e, em consequência, mais bem aceitos pelos consumidores. Grãos de arroz (Oryza sativa L.) cultivar "IRGA 417", cedidos pelo IRGA (Instituto Rio-Grandense do Arroz), foram utilizados em função do alto teor de amilose, característica importante na obtenção de extrato com maior teor de sólidos solúveis.

\subsection{Elaboração dos extratos de soja e de arroz}

O extrato de soja foi obtido com base nos procedimentos descritos por Mazza (1998), Liu (1999) e Barbosa (2007), que consiste, basicamente, nas operações de seleção de soja da cultivar "BRS 213", lavagem, maceração em água quente por 2 horas, trituração a quente em liquidificador e separação do resíduo por filtração. A proporção soja:água foi calculada para obtenção de extrato com aproximadamente $3 \%$ de proteínas $(\mathrm{m} / \mathrm{m})$.

O extrato de arroz foi obtido a partir de grãos de arroz da cultivar "IRGA 417" parboilizados. O processo de parboilização foi baseado em Elias (1998), nas seguintes condições: maceração por 6 horas à temperatura de $65^{\circ} \mathrm{C}$ e autoclavagem à pressão de $0,7 \mathrm{kgf.cm}^{-2}$. Antes do descascamento e após a autoclavagem, as amostras foram secas em estufa com circulação forçada de ar a $70^{\circ} \mathrm{C}$. A elaboração do extrato de arroz consistiu nas operações de trituração dos grãos, adição de água (15\% arroz: $85 \%$ água, $\mathrm{m} / \mathrm{m}$ ), autoclavagem a $121{ }^{\circ} \mathrm{C} / 15$ minutos e, após ajuste de condições favoráveis ( $\mathrm{pH} 5,2$ e $75^{\circ} \mathrm{C}$ ), foi adicionada a enzima $a$-amilase (Novozymes ${ }^{\circ}$ ). A ação enzimática sobre o amido foi conduzida até a obtenção de extrato com teor de sólidos solúveis de $10{ }^{\circ}$ Brix, seguido de filtração.

\section{Elaboração das bebidas de soja e arroz}

A elaboração das bebidas foi realizada pela mistura de quantidades diferentes de extratos de soja e de arroz. Foram desenvolvidas três formulações com as seguintes proporções $(\mathrm{m} / \mathrm{m})$ de extratos de soja e de arroz: 30:70, 50:50 e 70:30, padronizando-se o teor de sólidos solúveis em $10^{\circ} \mathrm{Brix}$, por adição de sacarose. As bebidas foram embaladas em recipientes plásticos e armazenadas sob refrigeração (aproximadamente $7^{\circ} \mathrm{C}$ ) até o momento das análises físico-químicas e sensoriais.

\subsection{Determinações físico-químicas nas bebidas de soja e arroz}

Nas bebidas com diferentes proporções de extratos de soja e de arroz (30:70, 50:50 e 70:30, m/m), a composição centesimal foi determinada conforme métodos descritos na Association of Official Analitycal Chemists - AOAC (AOAC, 1995), com exceção de carboidratos, que foram obtidos por diferença. E ainda, $\mathrm{pH}$ em potenciômetro digital ( $\mathrm{pHmeter}$ Digimed DM-20); acidez titulável, por titulação com solução de $\mathrm{NaOH} 0,1 \mathrm{~N}$ (AOAC $\left.n^{\circ} .947,05\right)$ com os resultados expressos em percentual de ácido fítico; sólidos solúveis, em refratômetro de bancada marca Analytikjena com correção da temperatura para $20^{\circ} \mathrm{C}$, expressos em ${ }^{\circ}$ Brix; açúcares redutores e totais, pelo método de Lane-Eynon, expressos em \% de glicose (INSTITUTO ADOLFO LUTZ, 1985); e viscosidade aparente, em viscosímetro rotacional Viscotester $6 \mathrm{~L} / \mathrm{R}$ da Termo Haake a $60 \mathrm{rpm}$ por 30 segundos, 
com spindle L1. Parâmetros semelhantes foram utilizados por Barbosa (2007) e Machado (2007) em avaliações de viscosidade aparente de bebidas à base de soja.

\subsection{Avaliação sensorial}

A avaliação sensorial das bebidas com diferentes proporções de extratos de soja e de arroz acrescidas de sacarose foi realizada em cabines individuais, com luz vermelha, com as amostras servidas em copos plásticos de coloração branca, com quantidades padronizadas (aproximadamente $10 \mathrm{~mL}$ ), refrigeradas a $10 \pm 2{ }^{\circ} \mathrm{C}$, codificadas com números aleatórios de três dígitos. Os testes foram realizados no Laboratório de Análise Sensorial do Departamento de Ciência dos Alimentos da Universidade Federal de Pelotas (DCA/UFPel). Participaram da avaliação sensorial provadores não treinados, de ambos os sexos, sendo estes alunos, professores e funcionários pertencentes à comunidade acadêmica da UFPel.

As bebidas foram apresentadas de forma casualizada aos provadores, que foram instruídos a beber água mineral entre as amostras para limpar o palato e neutralizar o sabor. Foram avaliadas sensorialmente por 80 provadores com idade entre 17 e 40 anos através de método afetivo, por meio de teste de ordenação (Figura 1), utilizando-se concomitantemente escala hedônica estruturada de 9 pontos, com os extremos se ancorando nos termos "9 - gostei muitíssimo" e "1 - desgostei muitíssimo” (Figura 2) (CHAVES; SPROESSER, 1993; MORAES, 1993; STONE; SIDEL; 1993; ABNT, 1994; GULARTE, 2002).

Nome:_Idade:_ Data:_____
Instruções: Você está recebendo amostras de bebida de soja e
arroz. Avalie as amostras e indique a sua preferência.
\[ \text { Código da amostra } \]
Mais preferida:
Menos preferida:
Explique as razões de sua preferência:

Figura 1. Ficha de avaliação sensorial utilizada no teste de preferência de bebidas de soja e arroz.

\begin{tabular}{|l|}
$\quad$ Escala hedônica \\
$1=$ desgostei muitíssimo \\
$2=$ desgostei muito \\
$3=$ desgostei regularmente \\
$4=$ desgostei ligeiramente \\
$5=$ indiferente \\
$6=$ gostei ligeiramente \\
$7=$ gostei regularmente \\
$8=$ gostei muito \\
$9=$ gostei muitíssimo
\end{tabular}

Figura 2. Escala Hedônica utilizada no teste de preferência de bebidas de soja e arroz.
Os resultados foram avaliados estatisticamente de acordo com a tabela de Kramer para verificação da significância do teste ao nível de 5\% (CHAVES; SPROESSER, 1993; STONE; SIDEL, 1993).

\section{Resultados e discussão}

\subsection{Determinações físico-químicas nas bebidas de soja e arroz}

$\mathrm{Na}$ Tabela 1 estão expressas as médias dos resultados das características físicas e da composição físico-química das três formulações de bebidas com diferentes proporções de extrato de soja e de arroz, padronizadas quanto ao teor de sólidos solúveis para $10^{\circ}$ Brix.

As bebidas de soja e arroz apresentaram todos os constituintes referentes à composição centesimal com teores proporcionais às matérias-primas de origem (Tabela 1). De acordo com Barbosa (2007), grãos de soja cultivar BRS 213 apresentaram aproximadamente $35,16 \%$ de proteínas, 20,01\% de lipídios e $5,48 \%$ de cinzas, $5,13 \%$ de fibra bruta e $29,15 \%$ de carboidratos, dados semelhantes aos publicados por Ciabotti et al. (2006). Em relação a estes constituintes, o arroz apresenta índices bastante inferiores, Helbig (2007), em estudos com a mesma cultivar e também com arroz parboilizado, encontrou em torno de $9,18 \%$ de proteínas, 0,72\% de lipídios e 0,57\% de cinzas. Estes dados estão de acordo com resultados citados por Storck, Silva e Comarella (2005) para a cultivar IRGA 417, também parboilizada. O teor de fibra bruta e de carboidratos no arroz parboilizado é de, respectivamente, 1,37 e 88,16\% (HELBIG, 2007).

Tabela 1. Caracterização física e físico-química de bebidas formuladas com diferentes proporções de extratos de soja e de arroz, adicionadas de sacarose.

\begin{tabular}{|c|c|c|c|}
\hline Determinação & B30S:70A* & B50S:50A* & B70S:30A* \\
\hline Sólidos totais & $9,73 \pm 0,06^{c}$ & \multicolumn{2}{|c|}{$9,74 \pm 0,16 b^{c} 10,13 \pm 0,08$} \\
\hline Proteínas & $1,06 \pm 0,03^{c}$ & $1,49 \pm 0,05^{\mathrm{b}}$ & $2,10 \pm 0,04^{\mathrm{a}}$ \\
\hline & $0,50 \pm 0,02^{\mathrm{a}}$ & $0,60 \pm 0,09^{a}$ & $0,65 \pm 0,17^{a}$ \\
\hline Cinzas & $0,25 \pm 0,00^{c}$ & $0,28 \pm 0,00^{\mathrm{b}}$ & $0,32 \pm 0,00^{\mathrm{a}}$ \\
\hline Fibra bruta & $0,20 \pm 0,00^{\mathrm{a}}$ & $0,25 \pm 0,01^{\mathrm{a}}$ & $0,31 \pm 0,01^{\mathrm{a}}$ \\
\hline Carboidratos & & & \\
\hline $\mathrm{pH}$ & $5,95 \pm 0,01^{\mathrm{c}}$ & $6,07 \pm 0,01^{b}$ & $6,23 \pm 0,02^{\mathrm{a}}$ \\
\hline Acidez (\% em ácido fítico) & $0,06 \pm 0,01^{c}$ & $0,08 \pm 0,01^{\mathrm{b}}$ & $0,09 \pm 0,01^{\mathrm{a}}$ \\
\hline Sólidos sol & $10,00 \pm 0,00^{\mathrm{a}}$ & $10,00 \pm 0,00^{\mathrm{a}}$ & $10,00 \pm 0,00^{\mathrm{a}}$ \\
\hline Viscosidade af & $27,67 \pm 0,33^{\mathrm{b}}$ & $51,00 \pm 0,58^{\mathrm{a}}$ & $27,67 \pm 0,33^{b}$ \\
\hline $\begin{array}{l}\text { Açúcares } r \\
\text { (\% glicose) }\end{array}$ & $2,12 \pm 0,10^{\mathrm{a}}$ & $1,69 \pm 0,06^{\mathrm{b}}$ & $1,07 \pm 0,01^{\mathrm{c}}$ \\
\hline $\begin{array}{l}\text { Açúcares totais } \\
\text { (\% glicose) }\end{array}$ & $3,22 \pm 0,16^{\mathrm{a}}$ & $2,01 \pm 0,05^{\mathrm{b}}$ & $1,28 \pm 0,01^{c}$ \\
\hline \multicolumn{4}{|c|}{$\begin{array}{l}\text { Os valores correspondem à média de } 3 \text { repetições com estimativa de desvio padrão; } \\
\text { Médias na mesma linha que possuem letras distintas diferem significativamente entre si } \\
\text { pelo teste de Tukey ( } \mathrm{p} \leq 0,05) ;{ }^{*} 30 \mathrm{~S}: 70 \mathrm{~A} \text { - bebida com } 30 \% \text { de extrato de soja e } 70 \% \text { de } \\
\text { extrato de arroz; } 50 \mathrm{~S}: 50 \mathrm{~A} \text { - bebida com } 50 \% \text { de extrato de soja e } 50 \% \text { de extrato de arroz; } \\
70 \mathrm{~S}: 30 \mathrm{~A} \text { - bebida com } 70 \% \text { de extrato de soja e } 30 \% \text { de extrato de arroz; }{ }^{*} \text { Calculados } \\
\text { por diferença (Carboidratos = } 100 \text { - sólidos totais - cinzas - proteínas - lipídios - fibra } \\
\text { bruta). }\end{array}$} \\
\hline
\end{tabular}


$\mathrm{O}$ pH e acidez das bebidas diferiram significativamente $(\mathrm{p} \leq 0,05)$ entre si (Tabela 1$)$, dados confirmados com as características dos extratos de origem. Machado (2007), em estudo com extrato de soja da mesma variedade, encontrou $\mathrm{pH}$ de 6,5, e Rodrigues et al. (2007), trabalhando com extratos de arroz, obtiveram valores de $\mathrm{pH}$ em torno de 4,6. A acidez de extratos obtidos de grãos, farinha integral e isolado proteico de soja situou-se entre 0,03 e 0,05\% em ácido fítico (RODRIGUES, 2003). Jaekel, Silva e Rodrigues (2007) encontraram em bebida de arroz sabor morango 0,02\% em ácido fítico, decorrente da acidez do arroz e da polpa de morango $(20 \% \mathrm{~m} / \mathrm{m})$. A acidez de bebidas à base de soja é superior à de arroz, o que também foi evidenciado neste trabalho.

O teor de sólidos solúveis foi ajustado a $10{ }^{\circ}$ Brix através da adição de sacarose. Contudo, decorre principalmente do extrato de arroz, no qual o amido é hidrolisado, por enzimas amilolíticas, em moléculas de dextrose, maltose e glicose (SILVA et al., 2004). De acordo com Machado (2007), o extrato de soja apresenta teor de sólidos solúveis próximo a $3,5^{\circ} \mathrm{Brix}$. A adição de açúcar é recomendável do ponto de vista sensorial, aumentando a aceitabilidade dos produtos.

A viscosidade, parâmetro importante na aceitabilidade e controle de qualidade dos alimentos (BARBOSA, 2007), variou de 28 a $51 \mathrm{mPa}$ (Tabela 1). Estudos com extratos de soja com diferentes percentuais de sacarose, mostraram valores semelhantes de viscosidade com variações de 11 a $43 \mathrm{mPa}$ (BARBOSA, 2007). Em relação a bebidas de arroz, Russell e Delahunty (2004) citaram médias de viscosidade de 3,2 a 62,3 mPa, em bebidas sem e com adição de espessantes, respectivamente.

A viscosidade depende do teor de sólidos totais e da composição de proteínas, lipídios e fibras (OGUNTUNDE; AKINTOYE, 1991). Como no extrato de arroz, a ação da a-amilase causou a queda da viscosidade decorrente da hidrólise do amido em moléculas menores (JARDINE, 1991). Era esperado que a bebida com maior percentual de extrato de soja apresentasse maior viscosidade, não só pelo seu maior teor de proteínas, lipídios e fibras (Tabela 1), como também pela menor quantidade de extrato de arroz. Isto não foi observado, provavelmente pela instabilidade dos constituintes, que podem ter sedimentado em função da taxa de deformação aplicada $\left(60 \mathrm{~s}^{-1}\right)$ e do tempo (30 segundos), utilizados para determinação da viscosidade.

Os sistemas dispersos, quando em repouso, têm uma estrutura definida pela composição e natureza química das fases que os integram. De acordo com as características de ambas, a estrutura está configurada pela presença de moléculas de cadeia longa, de partículas solvatadas ou de flóculos ou agregados e, inclusive, podem estar entrelaçadas, em forma de rede, pela união de vários agregados (JARDINE, 1991).

Vários fatores são responsáveis pelo comportamento reológico de um fluido. A viscosidade de uma solução depende, além de sua composição química, da concentração, tamanho e forma das moléculas em suspensão, das conformações que adotam no solvente, das oscilações entre as ligações formadas e do número de colisões intra e intermoleculares (BUFFO; REINECCIUS, 2002).
Embora não tenha sido acompanhado o comportamento reológico das bebidas em estudo, verifica-se que, na taxa de deformação aplicada $\left(60 \mathrm{~s}^{-1}\right)$, a viscosidade aparente das bebidas com maior percentual de extrato de soja (70S:30A) e maior proporção de extrato de arroz (30S:70A) foi inferior àquela obtida com 50\% de ambos. Nsofor e Osuji (1997) propõem que a viscosidade dos extratos de soja tratados termicamente possa ser afetada pelo número de ligações cruzadas resultantes da associação entre polissacarídeos, parcialmente hidrolisados, e as proteínas solúveis e insolúveis, parcialmente desnaturadas. Isto, aliado ao processo enzimático de obtenção de extrato de arroz, no qual o amido é convertido em compostos de diferentes tamanhos e estruturas (glicose, maltose e oligossacarídeos), podem ser responsáveis por este comportamento das bebidas.

Os teores de açúcares redutores e totais foram mais elevados nas bebidas com maiores proporções de extrato de arroz, uma vez que o extrato de arroz é constituído por moléculas de diferentes açúcares, como glicose, maltose, dextrose, e outros, resultantes da hidrólise do amido (ROBINSON, 1998; SILVA et al, 2004).

\subsection{Avaliação sensorial das bebidas de soja e arroz}

Os resultados obtidos em relação aos totais de preferências pelos provadores para as bebidas com diferentes proporções de extrato de soja e de arroz encontram-se na Figura 3, na qual o valor mais elevado da soma de ordens indica a maior preferência dos provadores pelo produto.

Dentre as bebidas de soja e arroz, a formulação 70S:30A sobressaiu-se, apresentando maior preferência, com soma de ordens equivalente a 182, seguida da bebida 50S:50A e 30S:70A com, respectivamente, 150 e 148 (Figura 3). De acordo com a Tabela de Kramer para teste de ordenação, a amostra preferida (70S:30A) diferiu significativamente ( $\mathrm{p} \leq 0,05)$ das demais, as quais não diferiram entre si.

Embora as três bebidas apresentem o mesmo teor de sólidos solúveis ( $\left.10^{\circ} \mathrm{Brix}\right)$, a bebida com maior percentual de extrato de soja foi acrescida de quantidade mais elevada de sacarose para

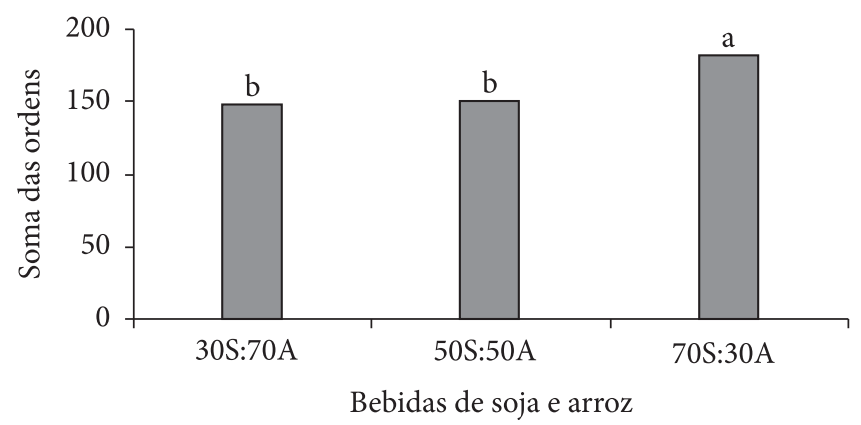

Figura 3. Preferência dos provadores pelas bebidas com diferentes proporções de extratos de soja e de arroz. Letras diferentes nas colunas indicam diferença significativa pelo teste de Kramer em nível de 5\% de probabilidade; 30S:70A - bebida com 30\% de extrato de soja e $70 \%$ de extrato de arroz; 50S:50A - bebida com 50\% de extrato de soja e $50 \%$ de extrato de arroz; 70S:30A - bebida com 70\% de extrato de soja e $30 \%$ de extrato de arroz. 
a padronização do teor de sólidos solúveis, já que o extrato de arroz possui maior teor destes, devido à presença de glicose, maltose, oligossacarídeos solúveis, como as maltodextrinas (ligeiramente doces) e dextrinas, decorrentes da hidrólise do amido por ação da $\alpha$-amilase (CEREDA et al., 2001; NUNES et al., 2006). Assim, como a doçura relativa da sacarose (100) é superior à da glicose (75), maltose (32) e de outros açúcares formados (SCHNEIDER, 2007), a bebida 70S:30A apresentou doçura mais pronunciada.

O gosto doce é ocasionado pela extremidade redutora dos açúcares que se combina na célula sensorial, desencadeando um processo que resulta na liberação de neurotransmissores. Os padrões de sinais gerados e transmitidos até o cérebro, a partir da liberação destes neurotransmissores, permitem a identificação do gosto doce do produto (MORAES, 1993).

A sacarose mascara o "sabor de feijão" da soja, aumentando a preferência dos provadores por extratos de soja adoçados (FAVARO TRINDADE et al., 2001). Além disso, o uso de soja com baixa atividade de lipoxigenases, enzimas responsáveis pelo desenvolvimento de sabor desagradável, possibilitou a obtenção de bebida de soja com sabor e aroma agradáveis e, em consequência, preferido pelos provadores.

Através da escala hedônica os provadores registraram o quanto gostaram ou desgostaram das bebidas. As formulações 70S:30A e 30S:70A apresentaram notas muito semelhantes com médias de, respectivamente, 6,8 e 6,7, que correspondem a "gostei regularmente". A bebida com quantidades equivalentes de extratos de soja e de arroz (50S:50A) apresentou média de 5,9 , correspondente a "gostei ligeiramente".

Notas médias semelhantes foram observadas por Valim et al. (2003) em pesquisa com bebida funcional elaborada com extrato de soja e diferentes proporções de suco de laranja, a qual foi submetida à análise sensorial, correlacionado concentração de proteína e ácido cítrico. As bebidas constituídas de 37\% de extrato e $18 \%$ de suco concentrado apresentaram as melhores médias $(7,6$ a 6,8) em teste de aceitação com escala hedônica de nove pontos.

Comportamento semelhante ao do presente estudo foi evidenciado por Torrezan et al. (2004), que alcançaram médias entre 7 e 8 , correspondentes a "gostei moderadamente" e "gostei muito", respectivamente, em estudo com bebidas de soja sabor laranja.

Barbosa (2007), avaliando bebida à base de extrato de soja fermentado saborizado com diferentes percentuais de polpa de pêssego ( 10 a 20\%) e de sacarose ( 8 a 12\%), obteve notas médias para a preferência em relação ao sabor, variando entre 4,0 e 7,3 que correspondem, respectivamente, a "desgostei ligeiramente" e "gostei regularmente"; sendo que a média mais alta foi obtida para a bebida com $15 \%$ de polpa e $12 \%$ de sacarose. Tais dados evidenciam que o teor de açúcar é fator preponderante à quantidade de polpa de frutas em bebidas à base de soja na preferência dos provadores.

As médias da escala hedônica referentes à bebida preferida pelos provadores foram usadas para determinar o índice de aceitabilidade, conforme Figura 4.

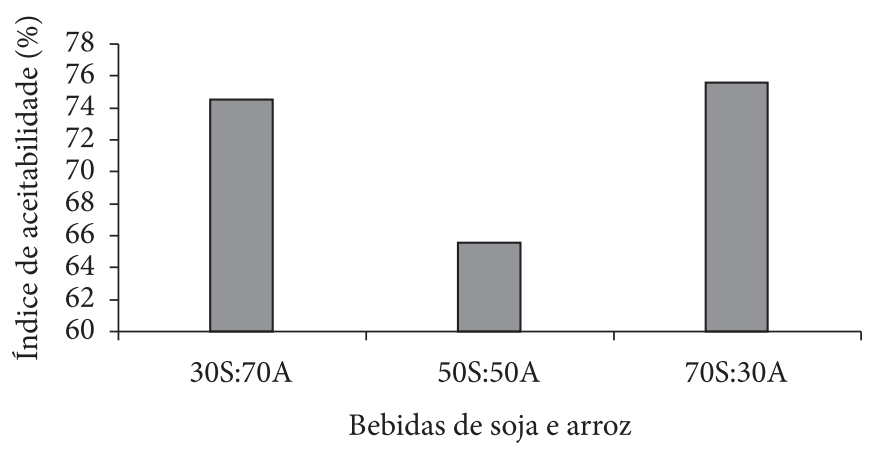

Figura 4. Índice de aceitabilidade das bebidas com diferentes proporções de extratos de soja e de arroz. 30S:70A - bebida com 30\% de extrato de soja e 70\% de extrato de arroz; 50S:50A - bebida com 50\% de extrato de soja e 50\% de extrato de arroz; 70S:30A - bebida com $70 \%$ de extrato de soja e $30 \%$ de extrato de arroz.

A bebida 70S:30A, que apresentou maior preferência, alcançou também maior índice de aceitabilidade (Figura 4), atingindo $75,6 \%$, seguida da bebida $30 \mathrm{~S}: 70 \mathrm{~A}(74,5 \%)$ e da 50S:50A (65,6\%).

De acordo com Gularte (2002), os produtos são considerados aceitos em termos de suas propriedades sensoriais quando atingem índice de aceitabilidade de no mínimo 70\%. Assim, as bebidas 70S:30A e 30S:70A foram consideradas aceitas pelos provadores, o que indica que os produtos apresentam características sensoriais adequadas e potencial para serem comercializados.

O extrato de soja apresentou índice de aceitabilidade de aproximadamente $43 \%$ em relação ao sabor no estudo de Machado (2007). A aceitação de extratos de soja na forma pura ainda é limitada, visto que a maioria dos extratos de soja prontos para o consumo disponíveis no mercado é acrescida de ingredientes que conferem doçura e/ou aromatizantes, com o intuito de mascarar o sabor característico de soja (RODRIGUES, 2003). Tal fato é confirmado no presente estudo: o extrato de soja associado ao de arroz e de sacarose apresentou maior aceitabilidade que o extrato de soja puro desenvolvido por aquele autor.

O estímulo ao consumo de produtos à base de soja deve estar associado não só aos constituintes nutricionais e funcionais inerentes a esta matéria-prima, como também a características sensoriais apreciáveis pelos consumidores, as quais podem ser facilmente obtidas, como demonstrado neste estudo em que a associação da soja com o arroz possibilitou a obtenção de bebida com características sensoriais agradáveis.

O atributo sabor é a propriedade sensorial que está associada aos teores de açúcares e acidez. A bebida preferida apresentou menor teor de açúcares redutores e totais, no entanto maior acidez, o que pode ter conferido equilíbrio ao produto, tornando seu sabor mais agradável.

Relacionando os resultados da avaliação sensorial com os das determinações físico-químicas, fica evidente a correspondência entre ambos, especialmente a relação entre o atributo sensorial sabor e os valores de açúcares, acidez e viscosidade. Neste estudo, além da sacarose e acidez, outros fatores podem ter 
contribuído para a maior aceitabilidade da formulação 70S:30A, como o uso de soja de baixa lipoxigenase e a viscosidade, já que as duas formulações mais aceitas (70S:30A e 30S:70A) apresentaram viscosidade iguais e mais baixa que a bebida com quantidades equivalentes de extrato de soja e arroz.

\section{Conclusões}

A bebida com $70 \%$ de extrato de soja e $30 \%$ de extrato de arroz (70S:30A) apresenta-se melhor em termos nutricionais, com maior teor proteico, lipídico, mineral (estimado pelo percentual de cinzas) e de fibras, que as bebidas com $50 \%$ de extrato de soja e $50 \%$ de extrato de arroz (50S:50 A) e com $30 \%$ de extrato de soja e $70 \%$ de extrato de arroz (30S:70 A). A bebida 70S:30A também apresentou maior preferência e maior índice de aceitabilidade que as demais, demonstrando que este produto apresenta potencial para ser comercializado. Contudo, a adição de suco de frutas ou de saborizantes poderia melhorar as características sensoriais do produto, já que bebidas à base de soja disponíveis no mercado geralmente são saborizadas .

\section{Agradecimentos}

À Fundação de Amparo à Pesquisa do Estado do Rio Grande do Sul (FAPERGS) e à Coordenação de Aperfeiçoamento de Pessoal de Nível Superior (CAPES) pelo apoio financeiro.

\section{Referências bibliográficas}

BARBOSA, E. G. Prevalência de bactéria probiótica L. acidophilus NCFM em extrato de soja fermentado e saborizado com sacarose e polpa de pêssego. 2007. 58f. Dissertação (Mestrado em Ciência e Tecnologia de Agroindustrial) - Faculdade de Agronomia Eliseu Maciel, Universidade Federal de Pelotas - UFPEL, Pelotas, 2007.

BERGER, A. et al. Similar cholesterol-lowering properties of rice bran oil, with varied gamma-oryzanol, in mildly hypercholesterolemic men. European Journal of Nutrition, v. 44, n. 3, p. 1-11, 2004.

BORRMANN, D. et al. Avaliação sensorial de bebidas a base de extrato hidrossolúvel de soja. In: CONGRESSO BRASILEIRO DE CIÊNCIA E TECNOLOGIA DE ALIMENTOS, 20., 2006, Curitiba, PR. Anais... Curitiba: SBCTA, 2006. 1 CD-ROM.

BUFFO, R. A.; REINECCIUS, G. A. Modeling the rheology of concentrated beverage emulsions. Journal of Food Engineering, v. 51, n. 4, p. 267-272, 2002.

CEREDA, M. P. et al. Propriedades gerais do amido. São Paulo: Fundação Cargill, 2001. 221p.

CHAMP, M.; FAISANT, N. Resistant starch: analytical and physiological aspects. Boletim da Ciência e Tecnologia de Alimentos, v. 30, n. 1 p. 37-43, 1996.

CHAVES, J. B. P.; SPROESSER, L. R. Práticas de laboratório de análise sensorial de alimentos e bebidas. Viçosa: Universidade Federal de Viçosa, 1993. 81p.

CIABOTTI, S. et al. Avaliações químicas e bioquímicas de grãos, extratos e tofus de soja comum e de soja livre de lipoxigenase. Ciência Agrotécnica, v. 30, n. 5, p. 920-929, 2006.

ELIAS, M. C. Espera para secagem e tempo de armazenamento na qualidade de arroz para semente e indústria. 1998. 164f. Tese (Doutorado em Ciência e Tecnologia de Sementes) - Faculdade de Agronomia, Universidade Federal de Pelotas, Pelotas, 1998.
FAVARO TRINDADE, C. S. et al. Development and sensory evaluation of soy milk based yoghurt. Archivos Latinoamericano de Nutrición, v. 51, n. 1, p. 100-104, 2001.

FERNANDES, S. M. et al. Caracterização química de extratos hidrossolúveis desidratados de arroz e soja. Pesquisa Agropecuária Brasileira, v. 35, n. 4, p. 843-847, 2000.

FRANCO, R. C. Análise comparativa de legislações referentes aos alimentos funcionais. 2006. 167p. Dissertação (Mestrado em Nutrição Humana Aplicada) - Faculdade de Ciências Farmacêuticas, Universidade de São Paulo - USP, São Paulo, 2006.

GAZZONI, D. L. Alimentos Funcionais. Disponível em: <http:// www.gazzoni.pop.com.br/alimentos_funcionais.htm>. Acesso em: 29 jul. 2006.

GOÑI, I. et al. Analysis of resistant starch: a method for foods and food products. Food Chemestry, v. 56, n. 4, p. 445-449, 1996.

GULARTE, M. A. Manual de análise sensorial de alimentos. Pelotas: Universidade Federal de Pelotas, 2002. 59p.

HELBIG, E. Efeitos do teor de amilose e da parboilização do arroz na formação de amido resistente e nos níveis glicêmico e lipêmico de ratos Wistar. 2007. 89p. Tese (Doutorado em Ciência e Tecnologia Agroindustrial) - Faculdade de Agronomia Eliseu Maciel, Universidade Federal de Pelotas - UFPEL, Pelotas, 2007.

INSTITUTO ADOLFO LUTZ. Normas analíticas do Instituto Adolfo Lutz. 3 ed. São Paulo, 1985. 533p.

INSTITUTO DE PESQUISA, CAPACITAÇÃO E ESPECIALIZAÇÃO E FACULDADE CBES - IEPC. 2007. Disponível em: <www. institutoipce.com.br/index.php? cont $=$ noticias\&id $=54>$. Acesso em 20 out. 2007.

JAEKEL, L. Z.; SILVA, A. P.; RODRIGUES, R. S. Influência da polpa de morango nas características físico-químicas de bebida de arroz. In: SIMPÓSIO LATINO AMERICANO DE CIÊNCIA DOS ALIMENTOS, 7, 2007, Campinas. Anais... Campinas: SLACA, 2007. 1 CD-ROM.

JARDINE, J. G. Redução da viscosidade de extrato de café por processo enzimático. 1991. 298f. Dissertação (Mestrado em Tecnologia de Alimentos) - Faculdade de Engenharia de Alimentos, Universidade Estadual de Campinas, Campinas, 1991.

LIU, K. Soybeans: chemistry, technology and utilization. New York: Chapman \& Hall, 1999. 532p.

LOBO, A. R.; SILVA, G. M. L. Amido resistente e suas propriedades físico-químicas. Revista de Nutrição, v. 16, n. 2, p. 219-226, 2003.

MACHADO, M. R. G. Bebida de soja fermentada com Lactobacillus acidophilus: viabilidade celular, avaliação sensorial, armazenamento e resposta funcional. 2007. 101f. Tese (Doutorado em Ciência e Tecnologia Agroindustrial) - Faculdade de Agronomia Eliseu Maciel, Universidade Federal de Pelotas - UFPEL, Pelotas, 2007.

MAIA, L. H. et al. Características químicas dos mingaus desidratados de arroz e soja. Ciência e Tecnologia de Alimentos, v. 20, n. 3, p. 416-423, 2000.

MAZZA, G. Alimentos funcionales: aspectos bioquimicos y de procesado. Zaragoza: Acribia, 1998. 457p.

MITRA, A.; BHATTACHARYA, D.; ROY, S. Role of Resistant Starches Particularly Rice Containing Resistant Starches in Type 2 Diabetes. Journal of Human Ecology, v. 21, n. 1, p. 47-51, 2007.

MORAES, M. A. C. Métodos para a avaliação sensorial dos alimentos. 8 ed. Campinas: UNICAMP, 1993. 93p.

MORAIS, A. A.; SILVA, A. L. Soja: suas aplicações. Rio de Janeiro: Editora Médica e Científica, 1996. 259p. 
NAMRATHA, J.; ASNA, U.; PRASAD, N. N. Effect of storage on resistant starch content of processed ready-to-eat foods. Food Chemistry, v. 79, n. 3, p. 395-400, 2002.

NSOFOR, L. M.; OSUJI, C. M. Stability, rheology and chemical properties of soymilk concentrates developed from sprouted soybeans. Journal of Food Science and Technology, v. 34, n. 1, p. 33-40, 1997.

NUNES, A. G. et al. Processos enzimáticos e biológicos na panificação. 2006. Disponível em: <http://www.enq.ufsc.br/labs/ probio/disc_eng_bioq/trabalhos_grad/trabalhos_grad_2006-1/ panificacao.doc $>$. Acesso em: 07 jun. 2007.

OGUNTUNDE, A. O.; AKINTOYE, O. A. Measurement and comparison of density, specific heat and viscosity of cow's milk and soymilk. Journal of Food Engineering, v. 13, n. 3, p. 221-230, 1991.

PRATES, J. A. M.; MATEUS, C. M. R. Componentes com atividade fisiológica dos alimentos de origem animal. Revista Portuguesa de Ciências Veterinárias, v. 97, n. 541, p. 3-12, 2002.

ROBINSON, D. S. Bioquímica y valor nutritivo de los alimentos. Zaragoza, Espana: Editora Acribia, S.A., 1998. 516p.

RODRIGUES, R. S. Caracterização de extratos de soja obtidos de grãos, farinha integral e isolado protéico visando à formulação e avaliação biológica (em coelhos) de bebida funcional à base de soja e polpa de pêssego. 2003. 177p. Tese. (Doutorado em Ciência e Tecnologia de Alimentos) - Faculdade de Engenharia de Alimentos, Universidade Estadual de Campinas, Campinas, 2003.

RODRIGUES, R. S. et al. Características físico químicas del extracto de arroz elaborado con malte de la cevada y del arroz In: CONGRESO ARGENTINO DE CIENCIA Y TECNOLOGÍA DE ALIMENTOS - CYTAL; SIMPOSIO INTERNACIONAL DE NUEVAS TECNOLOGÍAS, 9,2, 2007, Buenos Aires. Anais... Buenos Aires: CYTAL, 2007. 1 CD-ROM.

RUSSELL, K.; DELAHUNTY, C. The effect of viscosity and volume on pleasantness and satiating power of rice milk. Food Quality and Preference, v. 15, p. 743-750, 2004.
SALGADO, S. M. et al. Aspectos físico-químicos e fisiológicos do amido resistente. Boletim CEPPA, v. 23, n. 1, p. 109-122, 2005a.

SALGADO, S. M. et al. Modificação da concentração de amido resistente em feijão macassar (Vigna unguiculata L. Walp) por tratamento hidrotérmico e congelamento. Ciência e Tecnologia de Alimentos, v. 25, n. 2, p. 259-264, 2005b.

SCHNEIDER, C. D. Nutrição esportiva: Macronutrientes. 2007. Disponível em: <http://:www.pucrs.br/fefid/pos/saudedesporto/ disciplinas/nutesp/Aula_1_macronutrientes.pdf $>$. Acesso em: 09 dez. 2007.

SILVA, M. C. et al. Processamento de amido de milho em câmara de mistura. Revista Ciência e Tecnologia de Alimentos, v. 24, n. 2, p. 303-310, 2004.

STONE, H.; SIDEL, J. Sensory evaluation practices. New York: Academic Press, 1993. 337p.

STORCK, C. R.; SILVA, L. P.; COMARELLA, C. G. Influência do processamento na composição nutricional de grãos de arroz. Alimentos e Nutrição, v. 16, n. 3, p. 259-264, 2005.

THOMPSON, D. B. Strategies for the manufacture of resistant starch. Food Science e Technology, v. 11, n. 7, p. 245-253, 2000.

TORREZAN, R. et al. Avaliação do perfil sensorial de alimento com soja sabor laranja. Boletim do CEPPA, v. 22, n. 2, p. 199-216, 2004.

VALIM, M. F. et al. Sensory acceptance of a functional beverage based on orange juice and soymilk. Brazilian Journal of Food Technology, v. 6, n. 2, p. 153-156, 2003.

WALTER, M.; SILVA, L. P.; DENARDIN, C. C. Rice and resistant starch: different content depending on chosen methodology. Journal of Food Composition and Analysis, v. 18, n. 4, p. 279-285, 2005.

WANG, S. H. et al. Influência da proporção arroz:soja sobre a solubilidade e as propriedades espumantes dos mingaus desidratados. Ciência e Tecnologia de Alimentos, v. 20, n. 1, p. 83-89, 2000.

WILSON, T. A. et al. Comparative cholesterol lowering properties of vegetable oils: Beyond fatty acids. Journal of the American College of Nutrition, n. 19, p. 601-607, 2000. 